\title{
Precipitation gradient determines the tradeoff between soil moisture and soil organic carbon, total nitrogen, and species richness in the Loess Plateau, China
}

\author{
Cong Wang a,b,c, Shuai Wang a,b, Bojie Fu ${ }^{\text {a,b,* }}$, Zongshan Li ${ }^{\text {a }}$, Xing Wu ${ }^{\text {a }}$, Qiang Tang ${ }^{\text {a }}$ \\ a State Key Laboratory of Urban and Regional Ecology, Research Center for Eco-Environmental Sciences, Chinese Academy of Sciences, P.O. Box 2871, Beijing 100085, China \\ b Joint Center for Global Change Studies, Beijing 100875, China \\ c University of Chinese Academy of Sciences, Beijing 100049, China
}

\section{H I G H L I G H T S}

- The interactions of soil-plant systems along precipitation gradient were captured.

- Precipitation constraint on soil-plant systems variables tradeoffs was detected.

- Implications for restoration management in the Loess Plateau were obtained.
G R A P H I C A L A B S T R A C T

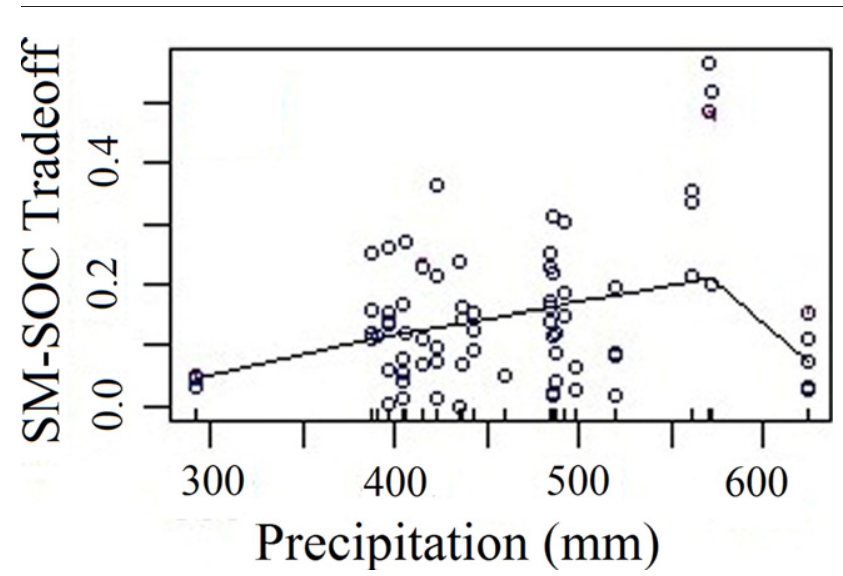

\begin{abstract}
A B S T R A C T
A tight coupling exists between biogeochemical cycles and water availability in drylands. However, studies regarding the coupling among soil moisture (SM), soil carbon/nitrogen, and plants are rare in the literature, and clarifying these relationships changing with climate gradient is challenging. Thus, soil organic carbon (SOC), total nitrogen (TN), and species richness (SR) were selected as soil-plant system variables, and the tradeoff relationships between SM and these variables and their variations along the precipitation gradient were quantified in the Loess Plateau, China. Results showed these variables increased linearly along the precipitation gradient in the woodland, shrubland, and grassland, respectively, except for the SR in the woodland and grassland, and SOC in the grassland $(p>0.05)$. Correlation analysis showed that the SM-SOC and SM-TN tradeoffs were significantly correlated with mean annual precipitation (MAP) across the three vegetation types, and SM-SR tradeoff was significantly correlated with MAP in grassland and woodland. The linear piece-wise quantile regression was applied to determine the inflection points of these tradeoffs responses to the precipitation gradient. The inflection point for the SM-SOC tradeoff was detected at MAP $=570 \mathrm{~mm}$; no inflection point was detected for SM-TN tradeoff; SM-SR tradeoff variation trends were different in the woodland and grassland, and the inflection points were detected at MAP $=380 \mathrm{~mm}$ and $\mathrm{MAP}=570 \mathrm{~mm}$, respectively. Before the turning point, constraint exerted by soil
\end{abstract}

\footnotetext{
* Corresponding author.

E-mail address: bfu@rcees.ac.cn (B. Fu).
} 
moisture on SOC and SR existed in the relatively arid regions, while the constraint disappears or is lessened in the relatively humid regions in this study. The results demonstrate the tradeoff revealed obvious trends along the precipitation gradient and were affected by vegetation type. Consequently, tradeoffs could be an ecological indicator and tool for restoration management in the Loess Plateau. In further study, the mechanism of how the tradeoff is affected by the precipitation gradient and vegetation type should be clarified.

(c) 2016 Elsevier B.V. All rights reserved.

\section{Introduction}

The strength and importance of couplings between ecological and hydrological dynamics has been a key driver force, which has led to the emergence of ecohydrology as a multidisciplinary research topic (Bond, 2003; Breshears, 2005; Caylor et al., 2009; Endreny, 2005; Hannah et al., 2004). Plants in the water-limited ecosystems are often considered to be water and nutrient limited (Rodríguez-Iturbe and Porporato, 2004), the interactions among plant, soil moisture and nutrient is complicated. Carbon and nitrogen availability are of great importance for plants and microorganisms in the dryland ecosystems, which further control many biogeochemical processes in the dryland, plant and microbial performance (Maestre et al., 2012). Biodiversity is the key driver of ecosystem functioning, which is also affected by other factors (Maestre et al., 2012). Soil moisture availability could affect the vegetation distribution and structure (D'Odorico et al., 2007; D'Odorico and Porporato, 2006; Ruiz-Sinoga et al., 2011a). Though the interaction between nutrient cycles and hydrology has been detected and studied for a long time, its consequences are still not completely understood (Rodríguez-Iturbe and Porporato, 2004). The effects of soil moisture on the carbon and nitrogen cycles have been extensively investigated in previous agricultural and ecological studies (Rodríguez-Iturbe and Porporato, 2004), studies on the interactions among the plants, soil nutrients, and soil moisture in the soil-plant system are relatively limited. It's necessary to clarify the interrelationships of water-soil-plant systems. Soil-water-plant systems are captured by many interrelationships, which make it difficult to study each element separately (RuizSinoga et al., 2011b). Soil moisture is fundamental in the tight coupling exists between ecosystem productivity, surface energy balance, biogeochemical cycles, and water resource availability in drylands (Wang et al., 2012), the central role of soil moisture in the soil-plant systems also needs to be explored.

The different interacting processes with many nonlinearities and feedbacks make the soil-plant system quite complex, it's difficult to characterize the interactions among the plants, soil nutrients, and soil moisture and explore the central role of soil moisture. Nonlinear analytical methods are needed to solve this problem. Tradeoff analysis detects the unidirectional changes with uneven paces or rates in objectives ( $\mathrm{Lu}$ et al., 2014). Tradeoff analysis could be applied to detect the interactions, trends, and drivers of multiple objectives (Lu et al., 2014), which is helpful for a throughout understanding on mechanisms of interactions among the objectives in the soil-plant systems along the environmental gradient. Jin et al. (2011) indicated that the transformation of precipitation into soil moisture and the soil water-retention could be affected by the physical and chemical properties of the soil (such as soil organic matter). Onaindia et al. (2013) indicated that biodiversity maintaining could sustain carbon sequestration and water flow regulation. While Chisholm (2010) indicated that afforestation for carbon sequestration might have adverse environmental impacts in the water-limited regions, leading to negative consequences for water supply and biodiversity. Tradeoff analysis among multiple ecosystems and the tradeoff relationships between other ecosystem indices have been conducted in recent studies, tradeoffs have proved to be an ecological indicator and tool for ecological management (Bagdon et al., 2016; Jia et al., 2014; Sun and Wang, 2016). Thus, the tradeoff analysis could be applied in this study to characterize the interrelationships of water-soil-plant systems, and explore the central role of soil moisture.
Vegetation cover, as well as the soil water availability, are strongly affected by climatic gradient (Choudhury et al., 2015). Ruiz-Sinoga and Martínez-Murillo (2009) found that the reduction in soil water availability would lead to the vegetation cover change, decline in organic matter content and soil aggregate stability. Climatic gradients also affect the soil clay content and the soil organic matter decomposition (Choudhury et al., 2015; Sheikh et al., 2009). Soil properties and hydrological processes would reveal spatial variations along the environmental gradient (altitudinal gradient, climatological gradient, recuperation gradient) (Campos et al., 2014; Cerdà, 1998a; Cerdà, 1998b; Choudhury et al., 2015; Vasconcellos et al., 2016). Thus, the environmental gradient would significantly affect the interrelationships of soil-water-plant systems, especially in the water-limited regions. The challenge of clarifying these relationships changing with climate gradient in the arid environments is daunting.

The Loess Plateau located in the middle reaches of the Yellow River basin in the northern China is the largest continuous loess region in the world (Lu et al., 2014). The highly erodible loessial soil, steep topography, frequent heavy rainfall in the growing season, sparse vegetation stemming and improper land use have led to severe soil erosion in the Loess Plateau (Gao et al., 2015). To control the severe erosion, a series of large scale restoration programs have been implemented, such as the Grain for Green project. The vegetation cover has changed dramatically since the Grain for Green project implementation, which altered the hydrological cycle. In addition, the regions is dominated by a monsoon climate and an obvious precipitation gradient exists from $200 \mathrm{~mm}$ in the northwest to $750 \mathrm{~mm}$ in the southeast (Feng et al., 2012). Thus, it's necessary to explore the interrelationships of the water-soil-plant systems along the precipitation gradient in the Loess Plateau. In this study, SOC (soil organic carbon) and TN (total nitrogen) were selected as variables representing carbon and nitrogen cycling; SR (species richness) was selected as a variable representing vegetation structure. The tradeoff between the soil moisture (SM) and SOC, TN, and SR and their variations with the precipitation gradient were examined in the Loess Plateau, China. Specifically, the objectives of this study are as follows: (1) to explore the differences of tradeoff between soil moisture and SOC, TN, and SR in grassland, shrubland, and woodland; (2) to analyse the variation of these tradeoffs with the precipitation gradient; and (3) to identify the inflection point of tradeoff responses to precipitation gradient.

\section{Materials and methods}

\subsection{Study sites and sampling design}

Field sampling and investigation took place between July and August in 2014. A total of 74 sampling plots were selected based on the vegetation type along a large precipitation gradient $(290 \mathrm{~mm}-620 \mathrm{~mm})$ in the Loess Plateau (Fig. 1). The sizes of woodland, shrubland, and grassland plots were set as $20 \times 20 \mathrm{~m}, 10 \times 10 \mathrm{~m}$, and $5 \times 5 \mathrm{~m}$, respectively. Three $2 \times 2 \mathrm{~m}$ subplots were randomly established for the vegetation survey in the woodland and shrubland plots. The plots encompass the representative restoration vegetation types in the Loess Plateau (grasslands, shrublands, and woodlands) (Table S1). The plots had similar landform characteristics (i.e., similar elevation, slight slope grade, and upper slope positions). Vegetation survey was conducted at each plot. In addition, the soil samples were collected at $0-100 \mathrm{~cm}$ with a $20 \mathrm{~cm}$ 


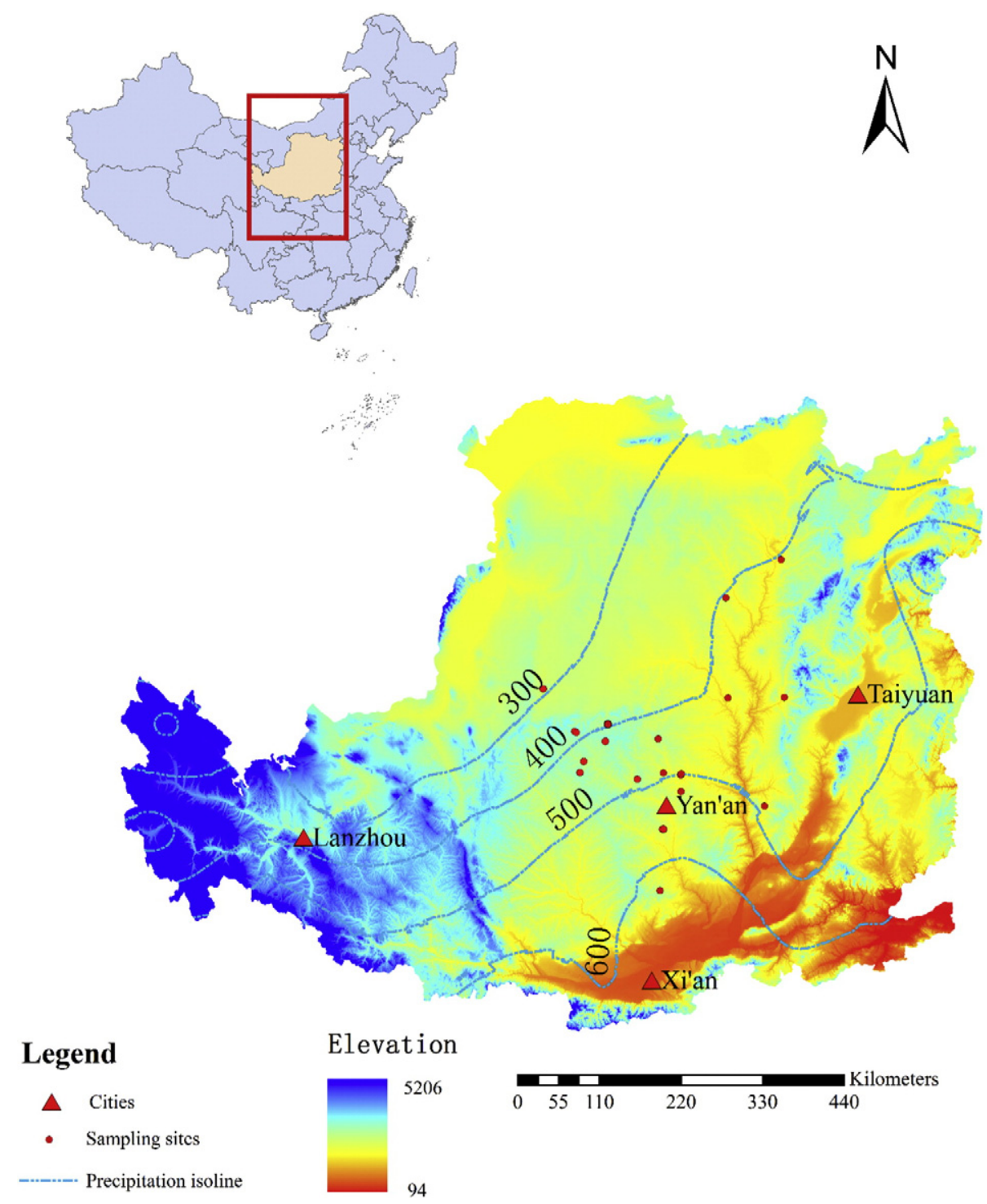

Fig. 1. Locations of the sampling sites selected in the Loess Plateau, China.

interval by using cylindrical core. The collected soil samples were airdried (for SOC and TN measurement) or preserved in sealed aluminum cans (for soil moisture content measurement) before lab analysis.

\subsection{Assessment of soil-plant system variables}

The potassium-dichromate oxidation method was used to determine SOC (Lu, 1999). The TN was estimated using the dry combustion method with a Vario EL Element Analyzer. The SM content was measured using the oven-dry method $\left(24 \mathrm{~h}\right.$ at $\left.105^{\circ} \mathrm{C}\right)$ in the laboratory. The amount of perennial species located in the quadrates was applied as an effort-standardized estimator of species richness, and only perennials were calculated as they contribute to maintaining ecosystem functioning and preventing desertification in dryland (Maestre and Escudero, 2009; Maestre et al., 2012; Whitford, 2002).

\subsection{Calculation of tradeoff}

The tradeoff relationship between SM and other variables could be quantified as described as follows:

Benefit for a single objective is defined as the relative deviation from the mean for a given observation by Bradford and D'Amato (Bradford and D'Amato, 2012). Given the observations of an objective $A$, the relative benefit of an objective $O B\left(B_{O B}\right)$ is defined as:

$B_{O B}=\frac{O B_{s}-O B_{\text {Min }}}{O B_{\text {Max }}-O B_{\text {Min }}}$

$\mathrm{RSMD}=\sqrt{\frac{1}{n-1} \cdot \sum_{i=1}^{n}\left(\mathrm{OB}_{i}-\overline{\mathrm{OB}}\right)^{2}}$

where $O B_{S}$ is an observed value of variable $O B$, and $O B_{\text {Min }}$ and $O B_{\text {Max }}$ are the minimum and maximum observed values; $\overline{O B}$ is the mean value of the $i$ number of $O B_{s}$. The trade-off is defined as the root mean squared error of the individual benefits (Eq. (2)), and increases with distance to the $1: 1$ line, where the benefit of two variables is equal (Bradford and D'Amato, 2012; Lu et al., 2014) (Fig. 2). This method provides an effective indicator for quantifying the relationships between soil moisture and other variables.

\subsection{Calculation of piecewise segment linear regression}

The linear piecewise quantile regression (LPQR) was applied to identify the response of tradeoff to precipitation as the potential constraint. 


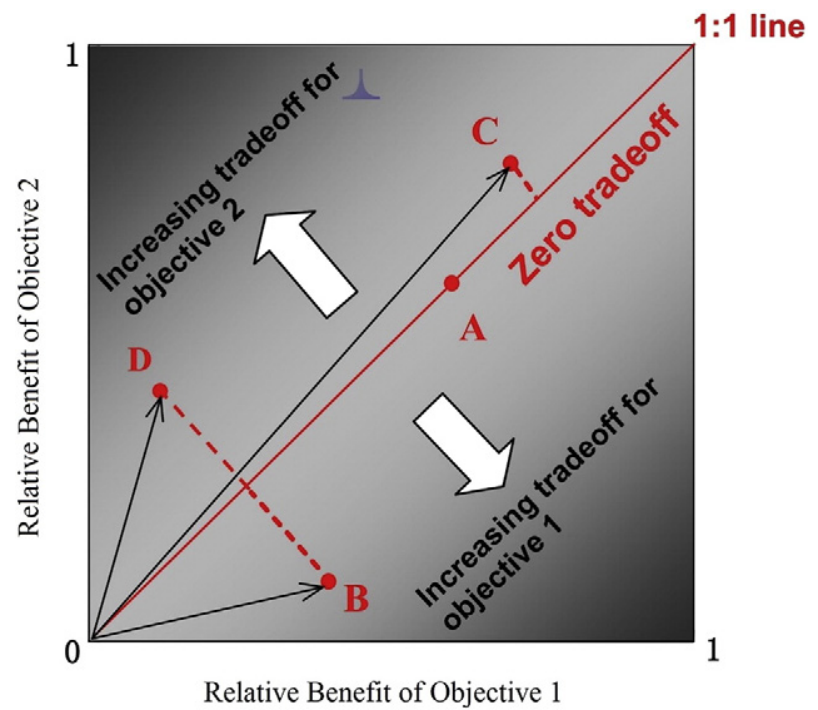

Fig. 2. Illustration of tradeoff between two objectives. The tradeoff is calculated as the root mean square error of the individual benefits. The relative position of the point to the 1:1 line indicates which objective is more beneficial at the given condition. Point $\mathrm{D}$ is more beneficial for objective 2 and point $B$ is more beneficial for objective 1 . The tradeoff at Point $C$ is smaller than that at Point B and Point D. The tradeoff at Point A is zero. This figure is modified from Lu et al. (2014).

LPQR could provide a flexible and robust analysis of heterogeneous datasets (Cade and Noon, 2003; Cottingham et al., 2005; Ruppert et al., 2012). A statistical solution to the examination of ecological limiting factors could be obtained using higher percentiles (Cade and Noon, 2003; Cox et al., 2006; Ruppert et al., 2012). As the significance of 99th percentile could not be tested (Sun and Wang, 2016), the 50th percentile was calculated for illustration purposes. The LPQR analysis was conducted with the quantreg package in the statistical software $R(R$ Core Development Team, R Foundation for Statistical Computing, Vienna, Austria).

\subsection{Other statistical analyses}

Correlation analysis was applied to detect the relationship between the tradeoff and the precipitation. Covariance was used to examine the differences of trade-offs among different ecosystem types. The relative frequency of tradeoffs is also calculated, which is the absolute frequency normalized by its total number.

\section{Results}

3.1. The variations of SM, SOC, TN, and SR and their tradeoffs in different vegetation types

The variations of SOC, TN, SM, and SR with precipitation gradient in each vegetation type were shown in Fig. 3. In the woodland, significant linear correlation exists between SOC and MAP, TN and MAP, and SM and MAP $(p<0.01$, and $p<0.05)$; in the shrubland, significant linear correlation exists between SOC and MAP, TN and MAP, SM and MAP, and SR and MAP $(p<0.01)$; in the grassland, significant linear correlation exists between TN and MAP, and SM and MAP $(p<0.01)$. The linear correlation results revealed that the variables selected in this study were strongly affected by the precipitation gradient, while the effects varied among the vegetation type. Thus, it's necessary to further explore the effects of MAP and vegetation type on these variables.

The relative frequency distribution (Fig. 4) showed that $<0.2$ accounted $70 \%$ of all SM-SOC tradeoffs in woodland with a mean value of $0.14 \pm 0.10$, shrubland with a mean value of $0.12 \pm 0.09$, and grassland with a mean value of $0.18 \pm 0.15 ;<0.2$ accounted $65 \%$ of all SM-TN tradeoffs in woodland with a mean value of $0.15 \pm 0.11$, shrubland with a mean value of $0.14 \pm 0.09$, and grassland with a mean value of $0.19 \pm$ $0.11 ;<0.2$ accounted $60 \%$ of all SM-SR tradeoffs in woodland with a mean value of $0.18 \pm 0.13$, shrubland with a mean value of $0.14 \pm$ 0.08 , and grassland with a mean value of $0.15 \pm 0.13$. The majority of these tradeoffs were relatively low, while there existed differences among different vegetation types.

\subsection{The relationships between tradeoffs and precipitation in different vege- tation types}

Pearson's correlation (Table 1) indicated that the SM-SOC tradeoff in grassland was significantly correlated with MAP; the SM-TN and SM-SR tradeoff in woodland and grassland were significantly correlated with MAP, respectively. No significant correlation existed between SM and other variables in shrubland. Interestingly, Table 1 showed that the SM-SOC and SM-TN tradeoff had positive significant correlations with MAP across the three vegetation types.

Covariance analysis (Table 2) showed that SM-SOC tradeoff was significantly affected by MAP, vegetation type, and their combination $(p<0.05, p<0.01)$; SM-TN tradeoff was significantly affected by the MAP; SM-SR tradeoff was significantly affected by vegetation type and combination of MAP and vegetation type.

\subsection{The response of tradeoffs along the precipitation gradient}

The response threshold and processes of tradeoff were examined along the precipitation gradient. Median percentiles (50th percentiles) were conducted to examine the precipitation gradient that acts as constraints on the tradeoffs.

The trends of SM-SOC and SM-TN tradeoffs for all the three vegetation types were shown in Fig. 5. The trend of SM-SOC tradeoff (50th percentile) was increased slightly and then rapidly decreased with the precipitation gradient. The inflection point was $570 \mathrm{~mm}$. The trend of SM-TN tradeoff (50th percentile) was increased with the precipitation gradient, and no inflection point was found in the studied gradient. As the SM-SR tradeoffs didn't significantly correlate with MAP as a whole, median percentiles (50th percentiles) were conducted in grassland and woodland (Fig. 6), respectively. In the woodland, the trend of SMSR tradeoff (50th percentile) was increased slightly and then rapidly decreased with the precipitation gradient. The inflection point was $380 \mathrm{~mm}$. In the grassland, the trend of SM-SR tradeoff (50th percentile) was increased rapidly and then slightly increased with the precipitation gradient. The inflection point was $570 \mathrm{~mm}$.

In addition, Fig. 5 showed that the relative value of SM tended to be higher than SOC in the relatively humid regions (MAP $>570 \mathrm{~mm}$ ), while SM tended to be lower than SOC in the relatively arid regions (MAP $<570 \mathrm{~mm}$ ); the relative value of SM tended to be higher than SR in grasslands in the relatively humid regions (MAP $>570 \mathrm{~mm}$ ) (Fig.6), while SM tended to be lower than SR in grasslands in the relatively arid regions (MAP $<570 \mathrm{~mm}$ ).

\section{Discussion}

\subsection{Explanations for the variations in tradeoffs}

The soil moisture and other three variables interact tightly with each other. The tradeoff analysis applied in this study essentially characterized the interactions between soil moisture and SOC, TN, and SR. Soil moisture could affect the amount and quality of litter, which in turns influences the soil organic matter decomposition rate (Rodríguez-Iturbe and Porporato, 2007), while soil organic matter (SOM) is also a critical factor influencing soil moisture by allowing the formation of stable aggregates (Barthes and Roose, 2002). For the nitrogen cycle, the effects of soil moisture on mineralization reflect on the balance between aeration (diminishing with soil moisture) and favorable humid conditions 

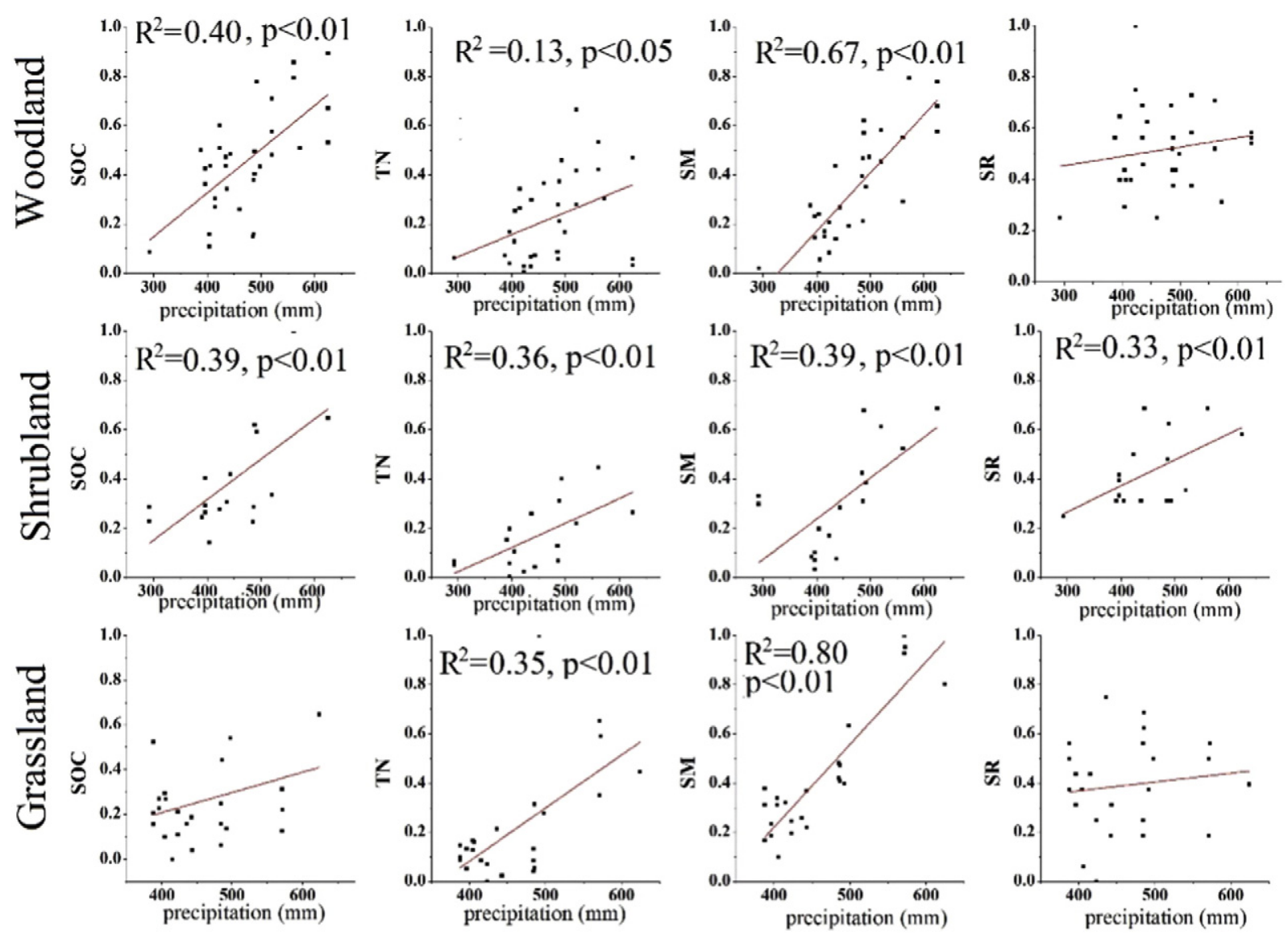

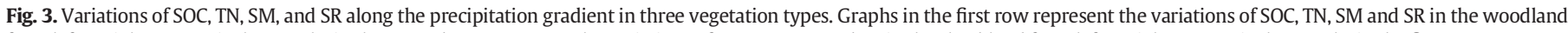

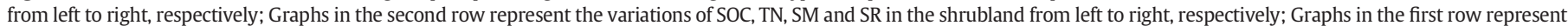
the variations of SOC, TN, SM and SR in the grassland from left to right, respectively.

for microbial biomass (Rodríguez-Iturbe and Porporato, 2007), while higher $\mathrm{N}$ availability would be beneficial for the mechanisms of stomatal control reducing the unproductive water losses (Brueck, 2008). The interactions between SR and SM are considered as the most complex issues because each species of plants is related to all the processes of soil moisture uptake as well as C and N cycling (Lu et al., 2014). Maestre et al. (2012) indicated that biodiversity could be an important driver to maintain multiple functions, such as carbon storage, productivity, and the buildup of nutrient pools, while obvious interactions exist between these multiple functions and the soil moisture. In addition, plant communities with more diverse species compositions could improve soil quality and structure (e.g., higher levels of SOM and nutrient content, greater permeability) (Chirino et al., 2006; Pinzari et al., 1999; Sardans and Peñuelas, 2013). The tradeoff analysis could provide a convenient tool to identify which process is dominant in the interactions and quantify their paces in the unidirectional changes along the precipitation gradient.

The tradeoff trends along the precipitation gradient indicated that the carbon sequestration or species maintaining are at the cost of soil water availability with the precipitation gradient decreasing. The constraint effects exert by soil moisture on soil carbon sequestration have also been detected in the Loess Plateau in recent study (Lu et al., 2014). The relative value of SR in woodland tended to be higher than SM along the precipitation gradient, while the SMSR tradeoffs decreased with the precipitation gradient in regions with MAP $>380 \mathrm{~mm}$. This also suggests species maintaining in the woodland is also at the cost of soil water availability. The soil moisture constraint exerts on SOC and SR could be explained that soil moisture is the foremost variable controlling many ecosystem processes in the water-limited regions and it might exert bottleneck for other variables (Lu et al., 2014). In addition, Pastor and Post (1986) found that the soil moisture limitation on soil nutrient and tree species increased with water-holding capacity decreasing along the soil texture gradient. Our results are consistent with their findings, as the soils are characterized by gradual fining in the size of particles from northwest to southeast due to the long term dust depositions in the Loess Plateau (Tsunekawa et al., 2014), and the water-holding capacity decreased with the precipitation decreasing. As for the SM-TN tradeoffs, the relative value of SM tended to be higher than TN along the precipitation gradient and their tradeoffs increased with the precipitation gradient. This indicated that the nitrogen sequestration might not be affected by the soil water availability along the precipitation gradient in this study area.

The variations of each individual variable selected in this study have been extensively explored in the Loess Plateau, while the tradeoff relationships between soil moisture and other three variables along the precipitation gradient were studied insufficiently. We found the SM-SOC and SM-TN tradeoffs revealed linear correlations with changing precipitation, regardless of the three vegetation types. In addition, SM-SR tradeoffs in grasslands and woodland also showed a linear correlation with changing precipitation. These indicated that the precipitation is the major determinant for the ecohydrological interactions in the soilplant systems in the Loess Plateau. In this study, the effects of vegetation type on the tradeoff relationships were further explored, the SM-SOC and SM-SR tradeoffs revealed obvious difference among different 

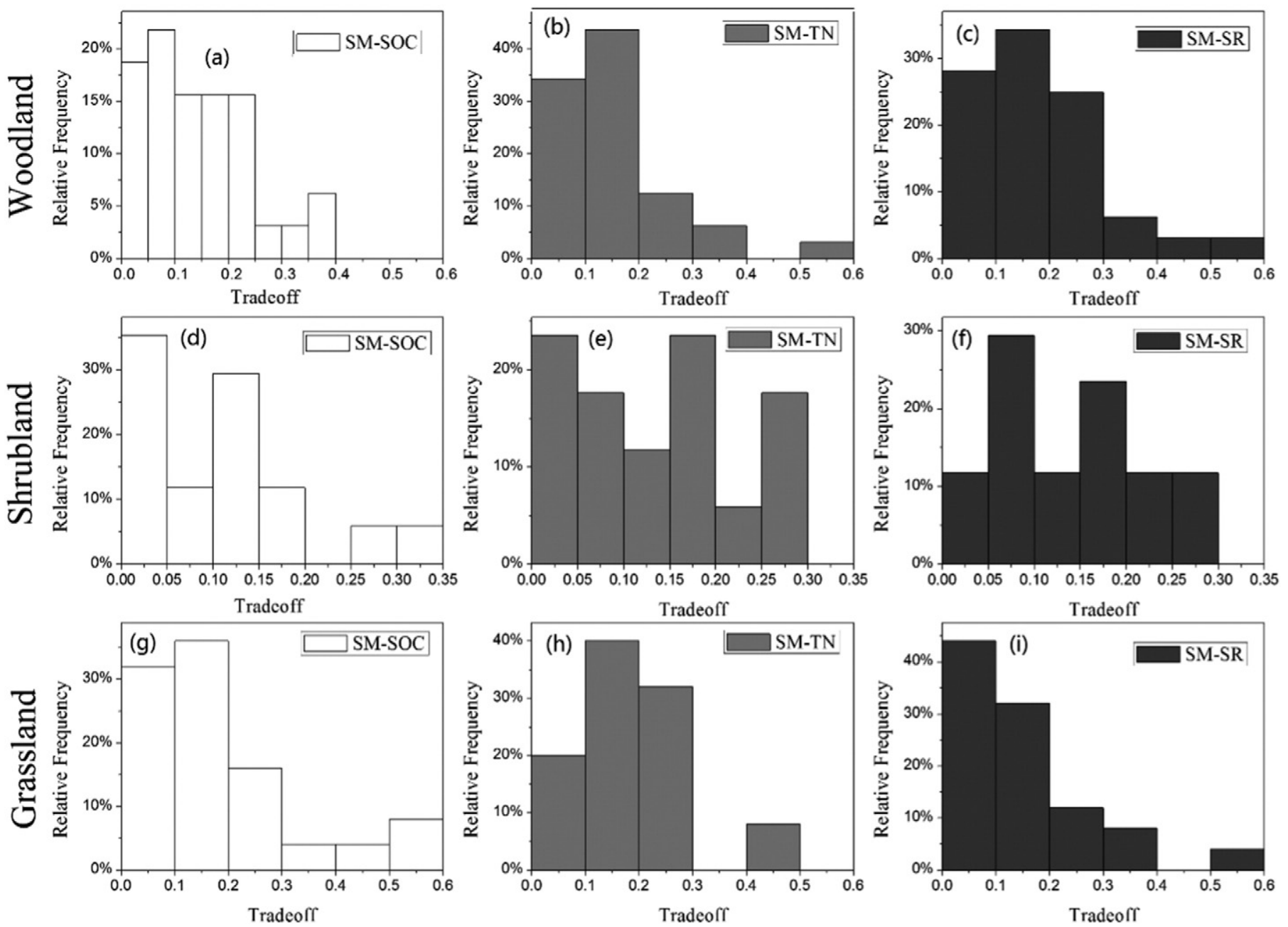

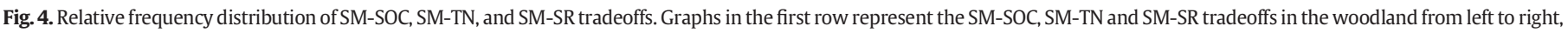

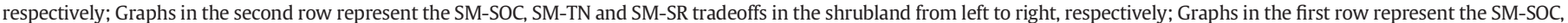
SM-TN and SM-SR tradeoffs in the grassland from left to right, respectively.

vegetation types, which could be attributed to the difference in the manner of resource utilization and partitioning among different vegetation types (Gamfeldt et al., 2013; Lu et al., 2014).

\subsection{Implications for restoration strategy and future prospects}

With the implementation of the restoration project in the Loess Plateau, the soil moisture pattern along the precipitation gradient with land use changing has altered greatly. Recent studies have showed that the soils of the Loess Plateau have been extensively dried in the semi-arid areas with the implementation of the restoration projects (Wang et al., 2010; Zhao et al., 2007). The dried soil would lead to intense constraint of soil moisture on SOC and SR, which would further affect the ecosystem stability in the Loess Plateau. It's necessary to evaluate the current restoration project implemented in the Loess Plateau. Recent studies have also shown that dwarfed trees occurred

Table 1

Relationships of tradeoffs with the MAP in different vegetation types.

\begin{tabular}{llll}
\hline & SM-SOC tradeoff & SM-TN tradeoff & SM-SR tradeoff \\
\hline Woodland & 0.025 & $0.587^{* *}$ & $-0.349^{*}$ \\
Shrubland & 0.238 & 0.325 & -0.073 \\
Grassland & $0.597^{* *}$ & $0.641^{* *}$ & $0.587^{* *}$ \\
Total & $0.290^{*}$ & $0.528^{* *}$ & 0.032 \\
\hline
\end{tabular}

* Represents $p<0.05$

** Represents $p<0.01$. throughout the reforestation regions with MAP $<400 \mathrm{~mm}$ in the Loess Plateau (Cao et al., 2011; McVicar et al., 2010). The soil moisture is generally considered as the limiting factor playing key roles in many terrestrial ecosystem processes especially in the water-limited regions, while its effects on these processes are not fully examined. Our study specified which process was affected by the soil moisture and identified the inflection point along the precipitation in the Loess Plateau. The new finding in this study would be helpful for providing a more scientific framework for restoration managing practice. Our results have confirmed that the constraint scope of soil moisture on SR was different between woodland and grassland (the scope of soil moisture constraint on SR in woodland in the study area is larger), which could be the proof that grassland restoration should be alternative approach for afforestation (Cao et al., 2011). In addition, multi-objective should be more considered in the restoration projects. Taking the Loess Plateau as an example, large-scale afforestation was implemented initially to control soil and water loss. Planting trees may fail to control soil and water erosion if the understory vegetation is damaged (Cao et al., 2011). Previous studies indicated that large areas dominated by a single species with

Table 2

Covariance analysis results for the tradeoffs in relation to MAP and vegetation type.

\begin{tabular}{llll}
\hline Source of variations & SM-SOC tradeoff & SM-TN tradeoff & SM-SR tradeoff \\
\hline MAP & 0.002 & $<0.001$ & 0.358 \\
Vegetation type & 0.011 & 0.209 & $<0.001$ \\
\hline
\end{tabular}



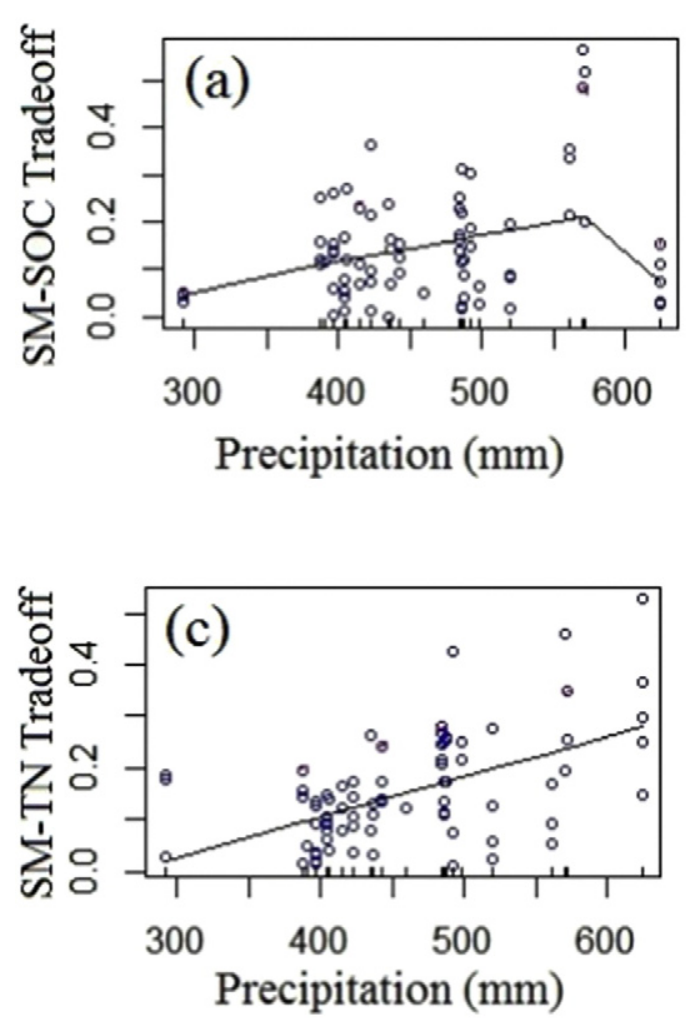
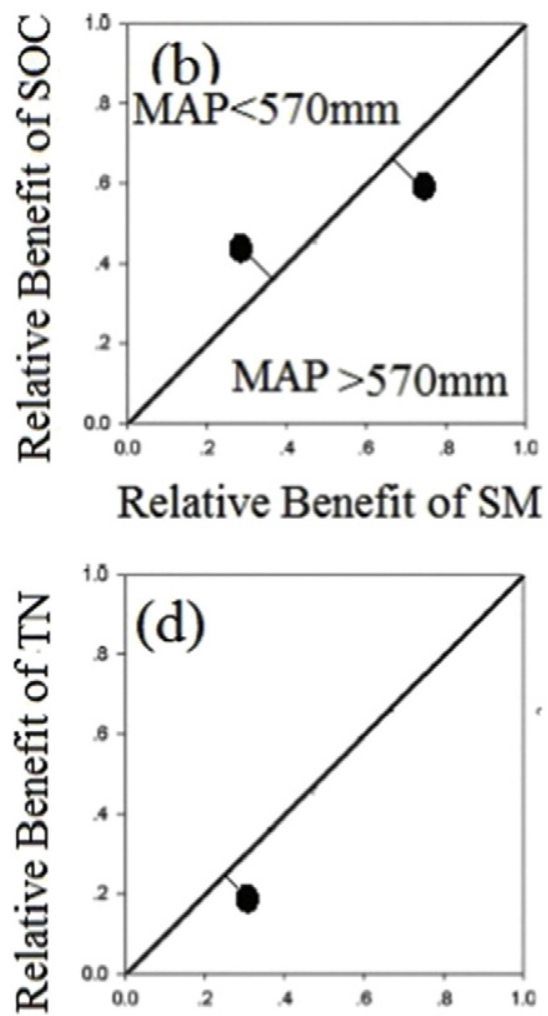

Relative Benefit of SM

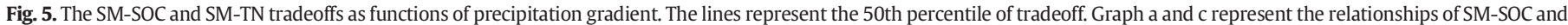
SM-TN tradeoffs with precipitation gradient, respectively. Graph b and d represent the relative positions of the data point.
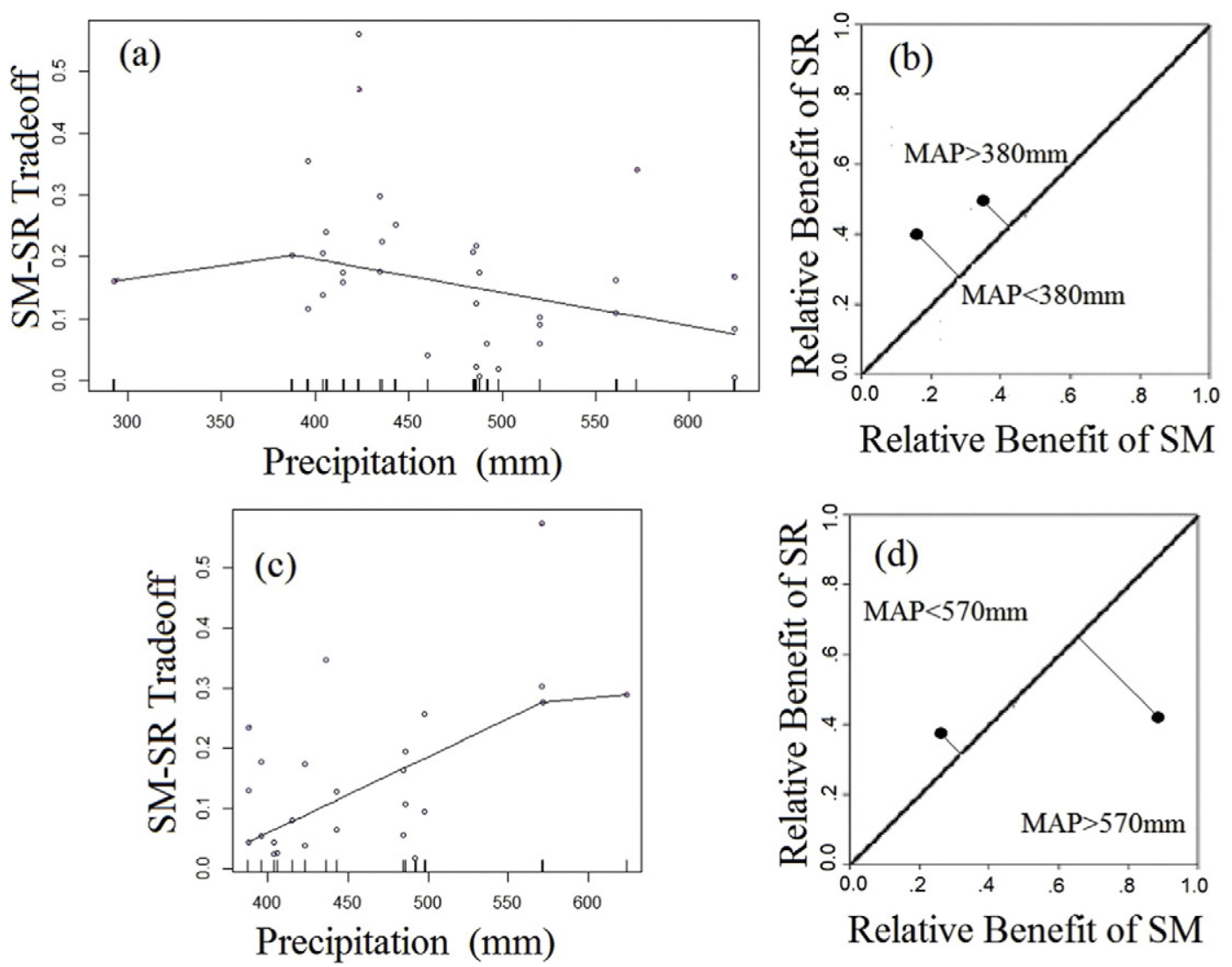

Relative Benefit of SM

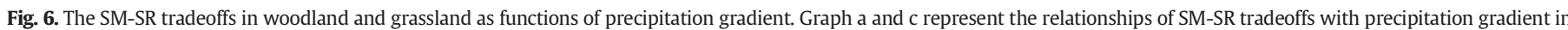
woodland and grassland, respectively. Graph $\mathrm{b}$ and $\mathrm{d}$ represent the relative position of the data point. 
low species richness might suffer from insect and disease problems (Stone, 2009; Wenhua, 2004). Carbon fixation and nutrient sequestration should also be incorporated into the management objectives in the restoration projects. Tradeoffs among different restoration goals should be carefully considered in the restoration projects.

\section{Conclusions}

The tradeoff analysis provides a new approach to characterize the interactions between soil moisture and other three variables in the soilplant system. In this study, the tradeoffs between SM and SOC, TN, and SR were analysed in the Loess Plateau, respectively. The effects of precipitation and vegetation type on these tradeoff relationships were detected. The tradeoffs of SM and SOC, SM and TN, and SM and SR revealed significant trends along the precipitation gradient, and inflection points were detected for SM-SOC tradeoffs and SM-SR tradeoffs, respectively. Though the mechanisms of tradeoffs differences among different vegetation types should be further explored, our results indicated the tradeoffs could be a scientific indicator and tool in the restoration management in the Loess Plateau.

Supplementary data to this article can be found online at http://dx. doi.org/10.1016/j.scitotenv.2016.10.047.

\section{Acknowledgement}

This work was funded by the National Natural Science Foundation of China [grant numbers 41390464, 41401027, 41501284], and the Chinese Academy of Sciences [grant number GJHZ 1502].

\section{References}

Bagdon, B.A., Huang, C.-H., Dewhurst, S., 2016. Managing for ecosystem services in northern Arizona ponderosa pine forests using a novel simulation-to-optimization methodology. Ecol. Model. 324, 11-27.

Barthes, B., Roose, E., 2002. Aggregate stability as an indicator of soil susceptibility to runoff and erosion; validation at several levels. Catena 47, 133-149.

Bond, B., 2003. Hydrology and ecology meet-and the meeting is good. Hydrol. Process. 17 2087-2089.

Bradford, J.B., D'Amato, A.W., 2012. Recognizing trade-offs in multi-objective land management. Front. Ecol. Environ. 10, 210-216.

Breshears, D.D., 2005. An ecologist's perspective of ecohydrology. Bull. Ecol. Soc. Am. 86 296-300.

Brueck, H., 2008. Effects of nitrogen supply on water-use efficiency of higher plants. J. Plant Nutr. Soil Sci. 171, 210-219.

Cade, B.S., Noon, B.R., 2003. A gentle introduction to quantile regression for ecologists Front. Ecol. Environ. 1, 412-420.

Campos, A., Etchevers, J., Oleschko, K., Hidalgo, C., 2014. Soil microbial biomass and nitrogen mineralization rates along an altitudinal gradient on the Cofre de Perote volcano (Mexico): the importance of landscape position and land use. Land Degrad. Dev. 25 581-593.

Cao, S., Sun, G., Zhang, Z., Chen, L., Feng, Q., Fu, B., et al., 2011. Greening China naturally Ambio 40, 828-831.

Caylor, K.K., Scanlon, T.M., Rodriguez-Iturbe, I., 2009. Ecohydrological optimization of pattern and processes in water-limited ecosystems: a trade-off-based hypothesis. Wate Resour. Res. 45

Cerdà, A., 1998a. Effect of climate on surface flow along a climatological gradient in Israel: a field rainfall simulation approach. J. Arid Environ. 38, 145-159.

Cerdà, A., 1998b. Relationships between climate and soil hydrological and erosional characteristics along climatic gradients in Mediterranean limestone areas. Geomorphology $25,123-134$

Chirino, E., Bonet, A., Bellot, J., Sánchez, J., 2006. Effects of 30-year-old Aleppo pine plantations on runoff, soil erosion, and plant diversity in a semi-arid landscape in south eastern Spain. Catena 65, 19-29.

Chisholm, R.A., 2010. Trade-offs between ecosystem services: water and carbon in a biodiversity hotspot. Ecol. Econ. 69, 1973-1987.

Choudhury, B.U., Fiyaz, A.R., Mohapatra, K.P., Ngachan, S., 2015. Impact of land uses, agrophysical variables and altitudinal gradient on soil organic carbon concentration of north-eastern Himalayan region of India. Land Degrad. Dev. 27, 1163-1174.

Cottingham, K.L., Lennon, J.T., Brown, B.L., 2005. Knowing when to draw the line: designing more informative ecological experiments. Front. Ecol. Environ. 3, 145-152.

Cox, S.B., Bloch, C.P., Stevens, R.D., Huenneke, L.F., 2006. Productivity and species richness in an arid ecosystem: a long-term perspective. Plant Ecol. 186, 1-12.

D'Odorico, P., Porporato, A., 2006. Dryland Ecohydrology. Springer.

D'Odorico, P., Caylor, K., Okin, G.S., Scanlon, T.M., 2007. On soil moisture-vegetation feedbacks and their possible effects on the dynamics of dryland ecosystems. J. Geophys. Res. Biogeosci. 112.
Endreny, T.A., 2005. Ecohydrology: a synthesis of Newtonian and Darwinian world views. Ecohydrology of water-controlled ecosystems: soil moisture and plant dynamics. I. Rodriguez-Iturbe and A. Porporato. Cambridge University Press ISBN 0-521-819431 Published 2005. Ecohydrology: Darwinian expression of vegetation form and function. Peter S. Eagleson. Cambridge University Press ISBN 0-521-77245-1 Published 2002. Hydrol. Process. 19, 2315-2317.

Feng, X.M., Sun, G., Fu, B.J., Su, C.H., Liu, Y., Lamparski, H., 2012. Regional effects of vegetation restoration on water yield across the Loess Plateau, China. Hydrol. Earth Syst. Sci. $16,2617-2628$.

Gamfeldt, L., Snäll, T., Bagchi, R., Jonsson, M., Gustafsson, L., Kjellander, P., et al., 2013. Higher levels of multiple ecosystem services are found in forests with more tree species. Nat. Commun. 4,1340.

Gao, G., Ma, Y., Fu, B., 2015. Temporal variations of flow-sediment relationships in a highly erodible catchment of the Loess Plateau, China. Land Degrad. Dev. 27, 758-772.

Hannah, D.M., Wood, P.J., Sadler, J.P., 2004. Ecohydrology and hydroecology: a 'new paradigm'? Hydrol. Process. 18, 3439-3445.

Jia, X., Fu, B., Feng, X., Hou, G., Liu, Y., Wang, X., 2014. The tradeoff and synergy between ecosystem services in the Grain-for-Green areas in Northern Shaanxi, China. Ecol. Indic. 43, 103-113.

Jin, T.T., Fu, B.J., Liu, G.H., Wang, Z., 2011. Hydrologic feasibility of artificial forestation in the semi-arid Loess Plateau of China. Hydrol. Earth Syst. Sci. 15, 2519-2530.

Lu, R., 1999. Analytical Methods of Soil Agrochemistry. China Agricultural Science and Technology Press, Beijing, pp. 85-96.

Lu, N., Fu, B., Jin, T., Chang, R., 2014. Trade-off analyses of multiple ecosystem services by plantations along a precipitation gradient across Loess Plateau landscapes. Landsc. Ecol. 29, 1697-1708.

Maestre, F.T., Escudero, A., 2009. Is the patch size distribution of vegetation a suitable indicator of desertification processes? Ecology 90, 1729-1735.

Maestre, F.T., Quero, J.L., Gotelli, N.J., Escudero, A., Ochoa, V., Delgado-Baquerizo, M., et al., 2012. Plant species richness and ecosystem multifunctionality in global drylands. Science 335, 214-218

McVicar, T.R., Van Niel, T.G., Li, L., Wen, Z., Yang, Q., Li, R., et al., 2010. Parsimoniously modelling perennial vegetation suitability and identifying priority areas to support China's re-vegetation program in the Loess Plateau: matching model complexity to data availability. For. Ecol. Manag. 259, 1277-1290.

Onaindia, M., Manuel, B.F.D., Madariaga, I., Rodríguez-Loinaz, G., 2013. Co-benefits and trade-offs between biodiversity, carbon storage and water flow regulation. For. Ecol. Manag. 289, 1-9.

Pastor, J., Post, W.M., 1986. Influence of climate, soil moisture, and succession on forest carbon and nitrogen cycles. Biogeochemistry 2, 3-27.

Pinzari, F., Trinchera, A., Benedetti, A., Sequi, P., 1999. Use of biochemical indices in the Mediterranean environment: comparison among soils under different forest vegetation. J. Microbiol. Methods 36, 21-28.

Rodríguez-Iturbe, I., Porporato, A., 2004. Ecohydrology of Water-controlled Ecosystems: Soil Moisture and Plant Dynamics. Cambridge University Press.

Rodríguez-Iturbe, I., Porporato, A., 2007. Ecohydrology of Water-controlled Ecosystems: Soil Moisture and Plant Dynamics. Cambridge University Press.

Ruiz-Sinoga, J.D., Martínez-Murillo, J.F., 2009. Eco-geomorphological system response variability to the 2004-06 drought along a climatic gradient of the Littoral Betic Range (southern Spain). Geomorphology 103, 351-362.

Ruiz-Sinoga, J., Galeote, M.G., Murillo, J.M., Marín, R.G., 2011a. Vegetation strategies for soil water consumption along a pluviometric gradient in southern Spain. Catena 84, $12-20$.

Ruiz-Sinoga, J.D., Galeote, M.A.G., Murillo, J.F.M., Marín, R.G., 2011b. Vegetation strategies for soil water consumption along a pluviometric gradient in southern Spain. Catena $84,12-20$.

Ruppert, J.C., Holm, A., Miehe, S., Muldavin, E, Snyman, H.A., Wesche, K, et al, 2012. Meta-analysis of ANPP and rain-use efficiency confirms indicative value for degradation and supports non-linear response along precipitation gradients in drylands. J. Veg. Sci. 23, 1035-1050

Sardans, J., Peñuelas, J., 2013. Plant-soil interactions in Mediterranean forest and shrublands: impacts of climatic change. Plant Soil 365, 1-33.

Sheikh, M.A., Kumar, M., Bussmann, R.W., 2009. Altitudinal variation in soil organic carbon stock in coniferous subtropical and broadleaf temperate forests in Garhwal Himalaya. Carbon Balance Manag. 4, 1 .

Stone, R., 2009. Nursing China's ailing forests back to health. Science 325, 556-558.

Sun, J., Wang, H., 2016. Soil nitrogen and carbon determine the trade-off of the above- and below-ground biomass across alpine grasslands, Tibetan Plateau. Ecol. Indic. 60, 1070-1076.

Tsunekawa, A., Liu, G., Yamanaka, N., S, D., 2014. Restoration and Development of the Degraded Loess Plateau. China Springer.

Vasconcellos, R.L., Bonfim, J.A., Baretta, D., Cardoso, E.J., 2016. Arbuscular mycorrhizal fungi and glomalin-related soil protein as potential indicators of soil quality in a recuperation gradient of the Atlantic Forest in Brazil. Land Degrad. Dev. 27, 325-334.

Wang, Y., Ma, S., Liu, Z., 2010. Large-scale spatial variability of dried soil layers and related factors across the entire Loess Plateau of China. Geoderma 159, 99-108.

Wang, L., d'Odorico, P., Evans, J., Eldridge, D., McCabe, M., Caylor, K., et al., 2012. Dryland ecohydrology and climate change: critical issues and technical advances. Hydrol. Earth Syst. Sci. 16, 2585-2603.

Wenhua, L., 2004. Degradation and restoration of forest ecosystems in China. For. Ecol. Manag. 201, 33-41.

Whitford, W.G, 2002. Ecology of Desert Systems. Academic Press.

Zhao, J., Du, J., Chen, B., 2007. Dried earth layers of artificial forestland in the Loess Plateau of Shaanxi Province. J. Geogr. Sci. 17, 114-126. 